\title{
LAMA RAWAT PADA PASIEN DENGAN CEDERA KEPALA RINGAN
}

\author{
Amila $^{1}$, Sariani² \\ 1Program Studi Ners, Universitas Sari Mutiara Indonesia. E-mail : mila_difa@yahoo.co.id \\ 2Fakultas Farmasi \& IImu Kesehatan Universitas Sari Mutiara Indonesia
}

\section{ABSTRACT : LENGTH OF STAY MILD HEAD INJURY IN SARI MUTIARA GENERAL HOSPITAL}

Background : Early management of head injury patient in hospital will affect the outcome and length of stay mild head injury patient in the hospital.

Purpose : The purpose of this study were to identify the correlation among age, GCS and hyperglycemia with length of stay in the hospital.

Methods :The data obtained was analyzed by correlational analytic with retrospective approach. The sample of this study was recruited with consecutive sampling as 117 people. Data collected by observation from medical record on the mild head injury patients who come to hospital from March 2014 until March 2015 at Sari Mutiara General Hospital Medan. The data was analyzed by pearson and spearman correlation with significance a $<0.05$.

Results : The study showed that $70.1 \%$ Hyperglicemia, mean of age, GCS and length of stay were $32.09 ; 13,99$ and 3.68 in mild head injury. There was no significantly correlation between age with length of stay $(r=0.163 ; p>$ $0.05)$. Whereas there was significant correlation between GCS and hyperglycemia with length of stay ( $r=-0.735 ; r$ $=0.610 ; p<0.05)$

Conclusion : Based on the study, we concluded that the more hyperglycemia, the more severe length of stay in patient with mild head injury.

Keywords: Mild head injury; GCS; Hyperglycemia; Length of stay

Pendahuluan: Penanganan awal pasien cedera kepala pada saat datang ke rumah sakit akan mempengaruhi outcome serta Length of Stay (LOS) pasien di rumah sakit

Tujuan : Penelitian ini bertujuan untuk mengetahui hubungan umur, GCS dan hiperglikemia dengan LOS pasien cedera kepala ringan di RSU Sari Mutiara Medan.

Metode : Metode penelitian dilakukan secara analitik korelasional dengan pendekatan retrospektif. Teknik sampling dalam penelitian ini menggunakan consecutive sampling dengan jumlah sampel sebanyak 117 orang yang diambil dari data sekunder yaitu observasi pada catatan medis pasien cedera kepala ringan yang dirawat di RSU Sari Mutiara Medan dalam periode satu tahun (Maret 2014 s.d Maret 2015). Data dianalisis menggunakan uji korelasi Pearson dan Spearman dengan signifikan a $<0.05$.

Hasil Penelitian: Hasil uji menunjukkan $70.1 \%$ pasien hiperglikemia, rata-rata umur pasien adalah 32.09 tahun, rata-rata GCS dan lama rawat pasien cedera kepala ringan adalah 13,99 dan 3.68 hari. Hasil uji menunjukkan tidak ada hubungan antara umur dengan LOS pasien cedera kepala ringan dengan nilai $p=0,080$ dengan kekuatan korelasi $r=0,163$. Hasil uji didapatkan hubungan yang signifikan antara GCS dan hiperglikemia dengan LOS pasien cedera kepala ringan ( $p=0,000)$ dengan kekuatan korelasi $(r=-0.735 ; r=0,610)$.

Simpulan : Hal ini menunjukkan bahwa semakin tinggi hiperglikemia, maka semakin tinggi LOS pasien cedera kepala.

Kata Kunci: Cedera kepala ringan, GCS, Hiperglikemia, Length of Stay

\section{PENDAHULUAN}

Cedera kepala merupakan penyebab utama mortalitas dan kecacatan di seluruh dunia serta merupakan masalah kesehatan umum yang sangat besar, bahkan di era ilmu kedokteran modern abad ke-21. Cedera kepala sering terjadi kasusnya ditiap tahun di dunia dan tidak sedikit pula orang meninggal dunia setiap tahunnya karena cedera kepala. Dan biasanya penyebab utama cedera kepala adalah kecelakaan lalu lintas. Diperkirakan 100.000 orang meninggal setiap tahunnya, dan lebih dari 700.000 mengalami cedera yang cukup berat yang memerlukan perawatan di rumah sakit (Hanura, 2017).

Salah satu dari negara negara berkembang seperti di Indonesia kematian cedera kepala sering diakibatkan oleh kecelakaan lalu lintas yang diperkirakan meningkat $83 \%$ pada tahun 2000- 
2020 dan kasus paling terbanyak adalah kasus cedera kepala (Widyaswara, 2016). Pevalensi cedera menunjukkan kenaikan dari 7,5 persen (Riskesdas, 2007) menjadi 8,2 persen (Riskesdas, 2013).

Setiap tahun sebanyak 200.000 kejadian cedera kepala membutuhkan perawatan di rumah sakit dimana 1,74 juta orang pasien dengan cedera 280 kepala sedang mengalami kecacatan sementara minimal 1 hari. Lama perawatan pasien cedera kepala di IGD berbeda-beda tergantung pada keparahan cedera pasien (Bethel, 2012). Pasien cedera kepala ringan selama 3 hari dengan lama perawatan minimum 1 hari dan maksimum 7 hari dan faktor yang paling berpengaruh dalam memprediksi lama perawatan pasien cedera kepala adalah GCS (Sipayung \& Syapitri, 2015).

Banyak faktor yang mempengaruhi outcome penderita cedera kepala ringan. Berbagai faktor yang telah diselidiki meliputi usia, mekanisme cedera kepala, skor awal glasgow coma scale (GCS), keadaan hipotensi, hiperglikemia, gambaran Ct scan, suhu tubuh dan konsentrasi laktat otak, diameter pupil dan reaksi cahaya, computed tomography (CT) scan, penggunaan alkohol dan obat-obat (Madikian 2006; Jiang, 2012). Beberapa Faktorfaktor seperti usia, jenis kelamin, keparahan cedera, kematian di rumah sakit, jenis asuransi dan lokasi rumah sakit sebagai prediktor biaya rumah sakit dan lama perawatan untuk cedera (Gardner, Smith, Chany, Fernandez, \& McKenzie, 2007).

Umur sebagai salah satu faktor cedera kepala ringan yang perlu diperhatikan karena semakin meningkat usia semakin besar angka kematian. Resiko outcome yang buruk paska cedera kepala semakin meningkat mulai usia 45 tahun dan meningkat tajam setelah usia lebih besar 55 tahun. Pada usia lebih besar 65 tahun angka kematian meningkat lebih dari dua kali dibandingkan usia kurang dari 65 tahun (Sastrodiningrat, 2007). Umur adalah faktor yang kuat dalam mempengaruhi prognosa, pada umumnya diketahui anakanak lebih baik daripada orang tua berusia lanjut. Pengaruh yang bermakna dari usia bukan karena adanya komplikasi sistemik atau hematoma intraserebral tetapi pertambahan usia. Meningkatnya usia adalah faktor independen di dalam prognosa; terjadi peningkatan outcome buruk yang bermakna pada usia $>60$ tahun (Sastrodiningrat, 2006).

Salah satu faktor yang memperlama rawatan pasien cedera kepala di Rumah Sakit adalah hiperglikemia. Hiperglikemia sering terjadi pada cedera kepala karena terjadi hiperosmolalitas yang mengakibatkan penurunan konsumsi oksigen sebesar $18 \%$ dan penurunan aliran darah ke otak sebesar $17 \%$ sehingga proses penyembuhan semakin lama dan memperburuk outcome pasien (Waspadji, 2007). Cedera kepala ditandai dengan adanya hipermetabolik dan hiperkatabolik. Hiperglikemia akan memicu terjadinya cedera sekunder yang akhirnya menyebabkan kerusakan sel sehingga memperburuk defisit neurologik pada penderita cedera kepala (Margulies 2009). Kadar glukosa darah yang lebih besar dari $200 \mathrm{mg} / \mathrm{dl}$ disebut hiperglikemia. Peningkatan gula darah tidak hanya meningkatkan angka mortalitas tapi juga meningkatkan angka morbiditas seperti infeksi nosokomial dan length of stay di Rumah Sakit (Godoy, 2011).

Salah satu alat ukur dalam menentukan outcome pasien cidera kepala dapat digunakan Glasgow Coma Scale (GCS) (Nurfaise, 2012). GCS merupakan instrumen standar yang dapat digunakan untuk mengukur tingkat kesadaran pasien cedera kepala ringan dengan skor 13-15, GCS juga dapat digunakan sebagai acuan pengobatan dan dasar pembuatan keputusan klinis umum untuk pasien (Nurfaise, 2012). Menurut Osler et al., (2016) bahwa GCS merupakan sebuah metode yang baik untuk mengukur kesadaran, prediktor outcome pasien, dan sebagai prediktor untuk melakukan evaluasi pada pelayanan trauma.

Pengelolaan cedera kepala yang benar dan tepat akan mempengaruhi outcome pasien. Tujuan utama pengelolaan cedera kepala adalah mengoptimalkan pemulihan dari cedera kepala primer dan mencegah cedera kepala sekunder. Cedera kepala primer terjadi saat benturan. Cedara kepala sekunder terjadi beberapa saat setelah terjadinya benturan dan biasanya dapat dicegah. Penyebab utama terjadinya cedera kepala sekunder adalah hiperglikemia, hipotensi dan peningkatan tekanan intrakranial. Pencegahan terjadinya cedera kepala sekunder pada kasus cedera kepala dapat memperbaiki outcome yang berbeda antara hidup atau meninggal dan mempengaruhi length of stay (Safrizal, 2013).

Hasil penelitian Sipayung (2014) bahwa terdapat hubungan signifikan hiperglikemia dengan length of stay pasien cedera kepala ringan di RSU Pringadi Medan dengan kekuatan korelasi sebesar 0,662 begitu juga antara GCS dengan LOS pasien cedera kepala ringan ada hubungan signifikan dengan kekuatan korelasi $r=0,829$. Nurfaise (2012) menunjukkan ada hubungan GCS dengan outcome

Amila' Program Studi Ners, Universitas Sari Mutiara Indonesia. E-mail : mila_difa@yahoo.co.id

Sariani ${ }^{2}$ Fakultas Farmasi \& Ilmu Kesehatan Universitas Sari Mutiara Indonesia 


\section{LAMA RAWAT PADA PASIEN DENGAN CEDERA KEPALA RINGAN}

penderita cedera kepala sedangkan Cochran dkk (2003) melakukan penelitian kadar gula darah pada penderita cedera kepala dimana didapatkan kadar gula darah yang lebih tinggi pada penderita cedera kepala yang meninggal dibandingkan pada penderita yang bertahan hidup $p=0,000$.

Hasil survey pendahululuan di bagian Medical Record Rumah Sakit Sari Mutiara Medan diperoleh data pasien cedera kepala terdapat 186 orang pada tahun 2014, dengan jumlah pasien laki-laki sebanyak 110 orang dan perempuan sebanyak 76 orang. Pada data tersebut 169 orang pasien rawat inap dengan cidera kepala ringan (CKR), 10 orang pasien rawat inap dengan cedera kepala sedang (CKS) dan 7 orang pasien rawat inap dengan cedera kepala berat (CKB). Rat-rata lama rawat pasien cedera kepala 4 hari, lama rawat paling cepat 1 hari dan paling Inama 11 hari untuk pasien cedera kepala ringan. Tujuan penelitian adalah mengetahui hubungan umur, GCS dan hiperglikemia dengan LOS pasien cedera kepala ringan di RSU Sari Mutiara Medan.

\section{METODE PENELITIAN}

Jenis penelitian ini adalah analitik korelasional dengan rancangan retrospective study dengan pengambilan data sekunder dari catatan medis pasien cedera kepala ringan yang dirawat di RSU Sari Mutiara bulan Maret 2014 s.d Maret 2015.

Populasi dalam penelitian ini adalah pasien cedera kepala ringan dengan jumlah sampel sebanyak 117 orang. Teknik sampel yang digunakan yaitu consecutive sampling. Penelitian ini menggunakan lembar observasi dan data yang diambil adalah umur, GCS saat masuk, hiperglikemia saat masuk dan lama perawatan dirumah sakit. Uji bivariat untuk mengetahui hubungan umur, GCS dan hiperglikemia dengan LOS pasien cedera kepala ringan di RSU Sari Mutiara Medan menggunakan Pearson dan uji Spearman.

\section{HASIL}

Tabel 1. Distribusi Frekuensi Hiperglikemia N=117

\begin{tabular}{lcc}
\hline Hiperglikemia (mg/dl) & $\mathbf{n}$ & $\%$ \\
\hline$<200$ & 35 & 29.9 \\
$>200$ & 82 & 70.1 \\
Total & 117 & 100 \\
\hline
\end{tabular}

Berdasarkan tabel 1. didapatkan distribusi frekuensi responden pada pasien cedera kepala ringan yang mengalami peningkatan kadar gula darah $<200 \mathrm{mg} / \mathrm{dl}$ sebanyak 35 orang $(29.9 \%)$ dan $>200 \mathrm{mg} / \mathrm{dl}$ sebanyak 82 orang $(70,1 \%)$.

Tabel 2. Distribusi Frekuensi Umur, GCS dan LOS N=117

\begin{tabular}{lcccccc}
\hline Variabel & $\mathbf{N}$ & Mean & SD & Min. & Mak. & $\mathbf{9 5 \%} \mathbf{C l}$ \\
& & & & & & \\
\hline Umur & 117 & 32,09 & 9,226 & 20 & 49 & $30,40-3378$ \\
GCS & 117 & 13,99 & 0,804 & 13 & 15 & $13,84-14,14$ \\
Length of Stay (LOS) & $\mathbf{1 1 7}$ & $\mathbf{3 , 6 8}$ & $\mathbf{1 , 1 8 8}$ & $\mathbf{2}$ & $\mathbf{7}$ & $\mathbf{3 , 4 6 - 3 , 8 9}$ \\
\hline
\end{tabular}

Berdasarkan pada data tabel 2 didapakan rata-rata umur adalah 32,09 tahun $(S D=9,226)$ dengan umur termuda 20 tahun dan umur tertua adalah 49 tahun. Dari hasil estimasi interval dapat disimpulkan bahwa 95\% diyakini bahwa umur rata-rata antara 30.40 tahun sampai dengan 33,78 tahun. Rata-rata GCS pasien adalah $13,99(S D=0,804)$ dengan GCS terendah adalah 13 dan tertinggi adalah 15. Dari hasil estimasi interval dapat disimpulkan bahwa $95 \%$ diyakini bahwa rata-rata glasgow coma scale pasien antara 13,84 sampai dengan 14,14 sedangkan rata-rata LOS pasien adalah 3,68 hari $(S D=1,188)$ dengan lama rawat terendah adalah 2 hari dan tertinggi adalah 7 hari. Dari hasil estimasi interval dapat disimpulkan bahwa 95\% diyakini bahwa rata-rata length of stay antara 3,46 hari sampai dengan 3,89 hari 
Tabel 3. Hasil Uji Korelasi Umur, Glasgow Coma Scale (GCS) dan Hiperglikemia dengan Length Of Stay (LOS) Pasien Cedera Kepala Ringan

\begin{tabular}{cc}
\hline Variabel & Length Of Stay (LOS) \\
\hline Umur & $\mathrm{p}=0,080$ \\
& $\mathrm{r}=0,163$ \\
\hline Glasgow Coma Scale (GCS) & $\mathrm{p}=0,000$ \\
& $\mathrm{r}=-0.735$ \\
\hline Hiperglikemia & $\mathrm{p}=0,000$ \\
& $\mathrm{r}=0,610$ \\
\hline
\end{tabular}

Berdasarkan tabel 3 didapatkan bahwa hasil uji pearson umur dengan LOS yaitu $(p=0,080>0,05)$ yang artinya tidak ada hubungan signifikan antara umur dengan LOS dengan nilai korelasi $(r=0,163)$ dengan kekuatan korelasi sangat lemah. Hasil uji Spearman yang didapatkan dari Glasgow Coma Scale (GCS) dengan Length Of Stay (LOS) yaitu ( $p=0.000: a=0.05)$. Adanya hubungan signifikan antara GCS dengan LOS dengan nilai korelasi ( $r=-$ 0.735) dengan kekuatan korelasi kuat. Hasil uji spearman hiperglikemia dengan Length of Stay (LOS) yaitu $(p=0.000: a=0.05)$, yang artinya ada hubungan signifikan antara hiperglikemia dengan LOS dengan nilai korelasi $(r=0.610)$ dengan kekuatan korelasi kuat.

\section{PEMBAHASAN}

\section{Hubungan Antara Umur Dengan Length of Stay Pasien Cidera Kepala Ringan}

Hasil penelitian yang dilakukan di RSU Sari Mutiara Medan menunjukkan usia tidak mempengaruhi lama rawat pasien cedera kepala dengan kekuatan korelasi $r=0,163$ menunjukan korelasi sangat lemah. Hasil penelitian ini berbeda dengan penelitian yang dilakukan Sastrodiningrat (2006) menyatakan adanya korelasi negatif antara umur yang bertambah dengan penyembuhan cedera kepala. Hukkelhoven, et al (2003) terhadap 5.600 orang pasien cidera kepala menunjukkan bahwa pasien cidera kepala dengan usia yang lebih tua selalu berpengaruh terhadap Length of Stay pasien di rumah sakit.

Didalam beberapa penelitian umur merupakan faktor yang mempengaruhi dalam penyembuhan pasien cedera kepala Sastrodiningrat (2006). Pada umur diatas 33 tahun outcome buruk adalah $67 \%$ sedangkan pada usia antara 15-25 tahun outcome buruk 56\%. Becker (2007) melaporkan angka mortalitas $22 \%$ untuk penderita cedera kepala di bawah umur 33 tahun dan $57 \%$ untuk umur diatas 65 tahun. Umur adalah salah satu faktor yang dapat mempengaruhi prognosa, pada umumnya disepakati bahwa umur muda bernasib lebih baik daripada orang-orang tua berumur lanjut. Memburuknya outcome pada pasien cidera kepala dengan usia diatas 55 tahun disebabkan oleh penurunan fungsi tubuh dan menurunnya daya tahan tubuh pasien dalam perbaikan keruskan sel tubuh. Penurunan fungsi tubuh pasien usia tua dalam memperbaiki kerusakan pada pasien cidera kepala membutuhkan waktu penyembuhan yang lebih lama serta memperpanjang Length of Stay pasien di rumah sakit.

Tidak adanya hubungan usia dengan LOS pasien cedera kepala ringan mungkin dapat disebabkan oleh faktor selain usia. Rata-rata umur pasien dalam cedera kepala ringan di RSU Sari Mutiara dalam penelitian ini adalah 32,09 tahun dengan umur termuda 20 tahun dan umur tertua adalah 49 tahun.

\section{Hubungan antara GCS dengan Length Of Stay Pasien Cidera Kepala Ringan}

Hasil penelitian yang dilakukan di RSU Sari Mutiara Medan menunjukkan bahwa GCS dengan LOS pasien cedera kepala ringan mempunyai hubungan yang signifikan dengan nilai $p=0.000$ dan koefisien korelasi $r=-0.735$ menunjukan korelasi negatif dengan korelasi kuat. Korelasi negatif menunjukan hubungan yang berbanding terbalik dimana semakin tinggi variabel independen maka semakin rendah variabel dependen. Artinya ialah semakin besar Glasgow Coma Scale maka semakin rendah Length Of Stay pasien cedera kepala ringan. GCS merupakan faktor prediksi yang kuat dalam menentukan prognosis, suatu skor GCS yang rendah pada awal cedera berhubungan dengan prognosis yang buruk dan lama rawat pasien.

Amila' Program Studi Ners, Universitas Sari Mutiara Indonesia. E-mail : mila_difa@yahoo.co.id Sariani ${ }^{2}$ Fakultas Farmasi \& Ilmu Kesehatan Universitas Sari Mutiara Indonesia 


\section{LAMA RAWAT PADA PASIEN DENGAN CEDERA KEPALA RINGAN}

Hasil penelitian ini sejalan dengan Narayan (2007) yang menyatakan bahwa GCS merupakan salah satu petunjuk yang sangat penting dari kemajuan pasien cedera kepala. Penelitian yang dilakukan Vincent (2007) pada 181 pasien cedera kepala juga menunjukan bahwa pasien dengan GCS rendah memiliki lama rawat lebih tinggi. Penelitian yang sama dilakukan oleh Sipayung (2014) menunjukan bahwa ada hubungan signifikan GCS dengan LOS pasien cedera kepala ringan di RSU Pringadi Medan dengan koefisien korelasi sebesar $r=0,829$. Penelitian ini juga didukung oleh Nurfaise (2012) menunjukkan ada hubungan GCS dengan outcome penderita cedera kepala.

GCS merupakan tolak ukur klinis yang digunakan untuk menilai beratnya cedera kepala. Penilaian GCS pasien dilakukan dengan menilai respon pasien cedera kepala, yaitu melihat respon mata, respon verbal dan respon motorik. Dari hasil penilaian GCS pasien dapat ditentukan menggambarkan keadaan neurologis pasien. Semakin rendah nilai GCS maka keadaan neurologis pasien semakin buruk. Menurut Osler et al., (2016), bahwa GCS merupakan sebuah metode yang baik untuk mengukur kesadaran, prediktor outcome pasien, dan sebagai prediktor untuk melakukan evaluasi pada pelayanan trauma. Pada penelitian di Provinsi Sancti Spiritus, Kuba, dilaporkan bahwa pemeriksaan GCS yang rendah dan glukosa darah yang tinggi disertai manifestasi berupa gagal napas dan pupil tidak bereaksi terhadap rangsang cahaya dapat memprediksi mortalitas pasien cedera kepala yang tinggi (Rodriguez, 2013).

Sastrodiningrat (2006), melaporkan bahwa 82\% dari penderita dengan skor GCS 11 atau lebih, dalam waktu 24 jam setelah cedera mempunyai good outcome atau moderately disabled dan hanya $12 \%$ yang meninggal atau mendapat severe disability. Outcome secara progresif akan menurun kalau skor awal GCS menurun. Di antara penderita dengan skor awal GCS 3 atau 4 dalam 24 jam pertama setelah cedera hanya $7 \%$ yang mendapat good outcome atau moderate disability. Diantara penderita dengan skor GCS 3 pada waktu masuk dirawat, $87 \%$ akan meninggal. Kehilangan kesadaran yang lama, dalam banyak hal tidak prediktif terhadap outcome yang buruk.

\section{Hubungan Antara Hiperglikemia Dengan Length of Stay Pasien Cidera Kepala Ringan}

Hasil penelitian yang dilakukan di RSU Sari Mutiara Medan menunjukkan ada hubungan hiperglikemia dengan LOS pasien cedera kepala ringan dengan kekuatan korelasi $r=0.610$ menunjukan kolerasi positif dengan kolerasi kuat. Kolerasi positif menunjukan hubungan yang berbanding lurus, dimana semakin tinggi variabel dependen maka semakin tinggi variabel dependen. Artinya ialah semakin tinggi hiperglikemia maka semakin tinggi juga LOS pasien cedera kepala. Hal ini menunjukan bahwa hiperglikeima yang terjadi pada 48 jam pertama setelah cedera berhubungan erat dengan length of stay. Hiperglikemi akan memacu terjadinya cedera kepala sekunder yang mengakibatkan terjadinya defisit neurologis karena kerusakan sel pada pasien cidera kepala. Menurut teori yang dikemukakan oleh Aritonang (2007) bahwa pada fase akut tubuh akan beradaptasi terhadap stress dan keadaan ini akan merangsang sekresi Growth Hormone (GH) atau hormon pertumbuhan dan katekolamin, dan perangsangan hormon-hormon tersebut akan meningkatkan kadar gula darah. Hasil penelitian ini sejalan dengan penelitian Waspadji (2007) yang menyatakan bahwa hiperglikemia yang terjadi saat pertama kali masuk rawatan yang menetap dan berkepanjangan pada pasien cedera kepala dapat meningkatkan lama kesembuhan dan length of stay pasien cedera kepala. Penelitian yang sama dilakukan oleh Sipayung (2014) menyatakan bahwa hiperglikemia dengan length of stay pasien cedera kepala ringan memiliki hubungan yang signifikan dan kekuatan kolerasi sebesar $r=0.662$. Berarti hiperglikemia saat cedera kepala sangat mempengaruhi length of stay pasien di rumah sakit apabila hiperglikemianya menetap dan berkepanjangan. Hiperglikemia umum terjadi setelah cedera primer dan berhubungan dengan keparahan cedera dan buruknya prognosis mortalitas dan perbaikan fungsional.

Begitu juga penelitian yang dilakukan oleh Wiryana (2008) mengenai hubungan hiperglikema dengan outcome pasien cedera kepala $p=0,000$. Sekitar $50 \%$ pasien menunjukkan kadar glukosa darah $>200 \mathrm{mg} / \mathrm{dl}$ dan level puncak yang lebih tinggi dari angka tersebut pada 24 jam pertama setelah masuk rumah sakit berhubungan dengan peningkatan resiko mortalitas dan status fungsional hingga 1 tahun pasca trauma.

Amila' Program Studi Ners, Universitas Sari Mutiara Indonesia. E-mail : mila_difa@yahoo.co.id Sariani ${ }^{2}$ Fakultas Farmasi \& llmu Kesehatan Universitas Sari Mutiara Indonesia 


\section{SIMPULAN}

Length of Stay rata-rata pasien cidera kepala ringan di RSU Sari Mutiara Medan selama 3 hari dengan lama rawat minimum 2 hari dan maksimum 7 hari. Penelitian ini menunjukkan tidak terdapat hubungan yang signifikan dengan kekuatan sangat lemah antara usia dengan LOS pasien cedera kepala ringan. Terdapat hubungan yang kuat antara GCS dan hiperglikemia dengan LOS pasien cedera kepala ringan di RSU Sari Mutiara Medan.

\section{SARAN}

Disarankan bagi manajemen rumah sakit untuk bisa mengidentifikasi pasien cedera kepala, memberikan penanganan yang tepat serta perawatan pasien cedera kepala sehingga lama rawat pasien menurun. Perlu penelitian selanjutnya untuk meneliti hiperglikemia dan glasgow coma scale dengan length of stay atau faktor-faktor lain seperti usia, hipotensi, mekanisme cedera dengan length of stay cedera kepala ringan di Rumah sakit lain.

\section{DAFTAR PUSTAKA}

Aritonang, S. (2007). Hubungan Kadar Gula Darah dengan Outcome cedera Kepala Tertutup Derajat Sedang-Berat dengan Gambaran Brain CT Scan Normal. Semarang: Universitas Diponegoro.

Bethel. (2012). Emergency Care of Children and Adults With Head Injury. Nursing Standard. (43), 49-56. Becker D., P., Miller J., D., Ward JD ., \& et al. (2007). The outcome from severe head injury with early diagnosis and intensive management. J Neurosurg

Cochran, A., Scaife, E. R., Hansen, K. W., \& Downey, E. (2003). Hyperglycemia And Outcomes From Pediatric Traumatic Brain Injury.

Gardner, S., Chany, F., \& McKenzie. (2007). Factors associated with hospital length of stay and hospital charges of motor vehicle crash related hospitalizations among children in the United States. Arch Pediatr Adolesc Med 2007, 161(9), 889-895.
Godoy, D.A., Napoli, M.D., Biestro, A., \& Leinhard, R. (2011). Perioperative Glukosa Control in Neurosergical Patient. Anesthesiologi Research ard Practice

Hanura, A. (2017). Jurnal Dinamika Kesehatan Status Fisiologis Pasien Cedera Kepala di IGD RSUD Ulin Banjarmasin, 8(1).

Hukkelhoven, C.W., Steyerberg., E.W., Rampean., A.J., \& Farace, E. (2003). Patient age and outcome following severe traumatic brain injury: an analysis of 5600 patients.

Jiang, J. (2012). Head trauma in China. Injury, Int. J.Care Injured 44 (2013) , 1453- 1457.

Narayan.(2007). Prognosis After Head Injury. In: Neurological surgery.

Nurfaise. (2012). Hubungan Derajat Cedera Kepala Dan Gambaran Ct Scan Pada Penderita Cedera Kepala Di RSU Dr. Soedarso

Osler, T., Cook, A., Glance, L. G., Lecky, F., Bouamra, O., \& Garrett, M., (2016). "The Differential Mortality of Glasgow Coma Score in Patients With and Without Head Injury." Injury, International Journal Care Injured 30:7.

Riset Kesehatan Dasar. (2013). Riset Kesehatan Dasar. Jakarta : Kementerian Kesehatan Republik Indonesia.

Rodriguez, M. (2013). Lessons from the field predicting mortality from head injury : experience of sancti spíritus province, Cuba lessons from the field. MEDICC. 15(3):30-3.

Sastrodiningrat, A. G. (2006). Memahami FaktorFaktor yang Mempengaruhi Prognosa Cedera Kepala Berat. Suplemen Majalah Kedokteran Nusantara Volume 39 No. 3 September 2006.

Safrizal, Saanin, S., \& Bachtiar. (2013). Hubungan nilai oxygen delivery dengan outcome rawatan pasien cedera kepala sedang. Padang: Universitas Andalas. 
Sipayung. (2014). Analisis Faktor-Faktor Prediktor Yang Berhubungan Dengan Length Of Stay Pasien Cidera Kepala Ringan Di Rsu Pirngadi Medan. Tesis. Malang : Fakultas Kedokteran Universitas Brawijaya. Tidak Dipublikasikan.

Sipayung, N. P., \& Syapitri, H. (2015). GCS sebagai prediktor length of stay pasien CKR di RSU Pringadi Medan. Medan. INJEC Vol 2 No 2 Okt 2015.indd.
Stead, LG., Bodhit, AN., Patel, PS .,\& Daneshvar, Y. (2013). TBI surveilance using the common data elements for traumatic brain injury: a population study. International Journal of Emergency Medicine 2013. (5):1-7.

Waspadji, S. (2007).Penatalaksanaan DiabetesMelitus Terpadu. Jakarta: Fakultas Kedokteran Universitas Indonesia.

Wiryana, M. (2008). Peranan Terapi Insulin Intensif Terhadap Interleukin Dan Luaran Klinik Pada Penderita Kritis Dengan hiperglikemia 